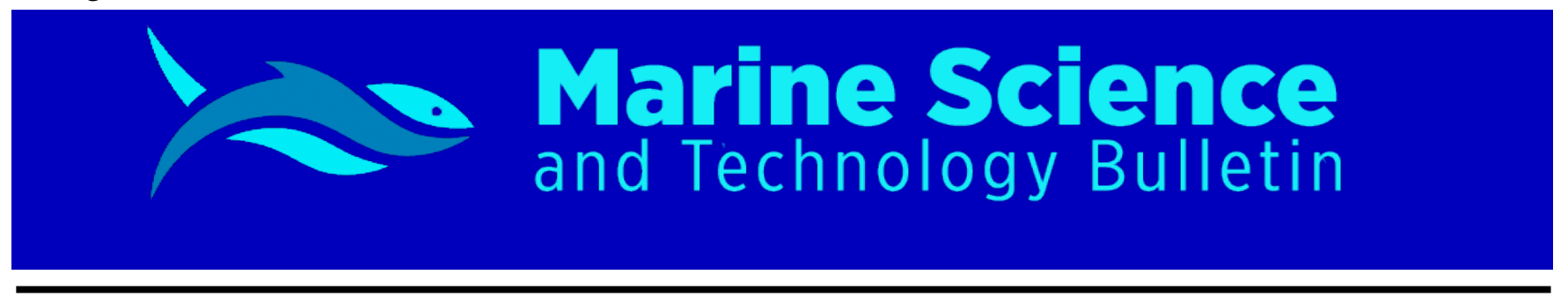

RESEARCH ARTICLE

\title{
Administration of different derivatives of Oliveria decumbens improves innate immunity of Nile tilapia (Oreochromis niloticus) without affecting
}

\section{fish growth and blood biochemical parameters}

\author{
Soheila Jalali ${ }^{1}$ (D) Arya Vazirzadeh $^{2^{*}}$ (D) Mostafa Akhlaghi $^{2}$ (D) Akbar Karami $^{3}$ \\ ${ }^{1}$ Shiraz University, School of Agriculture, Department of Natural Resources and Environmental Engineering, Shiraz 71441-65186, Iran \\ ${ }^{2}$ Shiraz University, School of Veterinary Medicine, Department of Aquatic Health and Diseases, Shiraz, Iran \\ ${ }^{3}$ Shiraz University, School of Agriculture, Department of Horticultural Science, Shiraz 71441-65186, Iran
}

\section{ARTICLE INFO}

Article History:

Received: 24.05.2020

Received in revised form: 13.09.2020

Accepted: 13.09.2020

Available online: 18.09.2020

Keywords:

Oliveria decumbens

Nile tilapia

Immunity

Growth

Health

\begin{abstract}
A B S TRACT
The objectives of this study were to investigate the effects of Oliveria decumbens as a medicinal herb with reported immunostimulatory potential on the growth, immunity status and health of Nile tilapia (Oreochromis niloticus). In an eight- week trial, fish (45 $\pm 5 \mathrm{~g}$ ) were randomly divided into 13 treatments as follows: in 10 treatments fish were fed on diets containing 0 (control), $0.01,0.1$ and $1 \%$ of $O$. decumbens extract and essential oil and their $1: 1$ combinations. Also, in three treatments fish received plant hydrolate at doses of 312.5, 625 and $1250 \mathrm{ppm}$ as bath treatment. At the end of experiment, blood samples were taken for immunological and biochemical measurements. All treated fish showed comparable growth performance to those received control diet. The highest levels of respiratory burst activity were observed in extract $1 \%$ group. Similarly the serum lysozyme levels were significantly affected by essential oil and extract supplemented diets. Fish received plant hydrolate at dose $312.5 \mathrm{ppm}$ showed the highest significant protein level. Also, the globulin levels were increased in group fed on diet containing extract $1 \%$. Plant supplementation had no negative effects on the fish health biochemical indices including cholesterol, triglyceride, alkaline phosphatase and aminotransferase enzymes. In conclusion, the results of this study showed that application of $O$. decumbens derivatives improved the immunity of Nile tilapia without adverse effects on fish growth and health.
\end{abstract}

Please cite this paper as follows:

Jalali, S. Vazirzadeh, A., Akhlaghi, M., Karami, A. (2020). Administration of different derivatives of Oliveria decumbens improves innate immunity of Nile tilapia (Oreochromis niloticus) without affecting fish growth and blood biochemical parameters. Marine

Science and Technology Bulletin, 9(2): 195-206.

\footnotetext{
* Corresponding author

E-mail address: vazirzadeh@shirazu.ac.ir (A. Vazirzadeh)
} 


\section{Introduction}

Variety of agents (viruses, bacteria, fungi and parasites) causes diseases in intensive aquaculture resulting in huge financial losses (Park and Choi, 2012; Dhayanithi et al., 2015). Antibiotics are commonly used in aquaculture industry to treat diseases, but they are criticized for the negative effects on fish and the environment. There has been a growing concern regarding antibiotic residue in human food and environment. Therefore, it is of great importance to find biodegradable, environmental friendly alternatives to replace antibiotics and other chemicals currently used in aquaculture sector for disease control (Tang et al., 2014).

Natural immunostimulants with the potentials to enhance the resistance against diseases by improving innate immune system are promising alternatives to antibiotics, vaccines and other artificial compounds (Divyagnaneswari et al., 2007; Van Hai, 2015). The effects of immunostimulants on aquatic organisms depend on multiple factors such as duration, dose and method of administration (Sakai, 1999; Divyagnaneswari et al., 2007). The immunostimulants usually use through oral, immersion or injection in aquatic animals (Sakai, 1999; Park and Choi, 2012).

It has been proven in previous studies that plant based immunostimulants improve the innate immune responses against bacterial, viral and parasitic diseases in freshwater and marine fishes and crustaceans (Tang et al., 2014). One of the most important advantages of using herbal immunostimulant in aquatic organisms is that they contain natural organic substances which do not harm fish, the environment or humans (Ardó et al., 2008; Van Hai, 2015; Brum et al., 2017).

Nile tilapia, Oreochromis niloticus (Linnaeus, 1758) is the second major aquaculture species in the world and has been considered as the main candidate for developing aquaculture in unconventional water resources because of its tolerance to environmental changes (Grammer et al., 2012; Brum et al. 2017). Extensive studies have been carried out on the effects of medicinal plants' extracts and essential oils as immunostimulants in aquatic organisms (Harikrishnan et al., 2009; Zhang et al., 2009; Adel et al., 2015; Safari et al., 2016). Also, improving the immune status in tilapia fish using herbal products has already been reported (Divyagnaneswari et al., 2007; Park and Choi, 2012; Tang et al., 2014; Gabriel et al. 2015). Oliveria decumbens Vent (Apiaceae) is a native medicinal plant to Iran and adjacent countries. Effective antimicrobial properties have been traditionally considered for this plant and confirmed recently against different bacteria (Alizadeh Behbahani et al., 2018). Yet, there is no study available on the effects of $O$. decumbens on innate immunity of Nile tilapia. Incorporation of extract or essential oils in diet is the most common method for application of herbal products in fish (Awad and Awaad, 2017). Oral administration is the most common route to use herbal oils and extracts in aquaculture, although there are some reports on the bath treatment of fish with herbal oils and extracts (Yilmaz and Ergun, 2012), mostly for external pathogen treatments (Andrade et al., 2016; Cunha et al., 2018). Despite the wide use of plant hydrolate -an aqueous composition that obtained via distillation method during essential oil extraction and contained some polar compounds - as the most common derivative of medicinal plants in human, the effects of medicinal plants' hydrolate have not been investigated on aquatic animals, unless our most recent studies evaluating the antibacterial activity of $O$. decumbens hydrolate on Nile tilapia resistance against Streptococcus iniae (Vazirzadeh et al., 2019). The objectives of this study were to evaluate the effects of essential oil, extract and hydrolate of $O$. decumbens on the innate immune, growth performance and blood health biochemical parameters in Nile tilapia.

\section{Material and Methods}

\section{Medicinal Plant}

Plant was collected from Khonj, southern Iran and was authenticated by morphological features as O. decumbens by experts in medicinal plants at Horticulture department of Shiraz University. The aerial parts of the plant, including stems and flowers, were dried at room temperature with proper ventilation for 4 weeks, and kept in a dry and cool place till use.

\section{Essential Oil and Hydrolate Extraction}

The dried plant $(20 \mathrm{~g})$ was powdered and the essential oil and hydrolate were extracted simultaneously by a semiindustrial Clevenger (Namagol, Isfahan-Iran) with water (100 $\mathrm{ml}$ per each $20 \mathrm{~g}$ plant materials) and by steam distillation method (Acar et al., 2015). During distillation, steam supplied from a boiler was passed through the plant materials and removed the essential oil out. The steam was then cooled using a condenser and the essential oil (the upper phase lighter than water) was separated from aromatic water or hydrolate by using a separation funnel. Finally, each $20 \mathrm{~g}$ plant materials yielded to $1 \mathrm{~g}$ essential oil (equal to $5 \%$ of plant materials used) and $75 \mathrm{~mL}$ hydrolate. The essential oil was kept at $-21^{\circ} \mathrm{C}$ until use. The obtained hydrolate was kept away from sunlight in a closed container at room temperature until use (Karami et al., 2019). 


\section{Hydroethanolic Extract}

Extract was prepared with maceration (soaking) method. In this procedure, $20 \mathrm{~g}$ herbal powder was mixed with $300 \mathrm{ml}$ of water and ethanol (70\%) with ratio of 1:15 (v:v). The mixture was stirred with a magnet for $1 \mathrm{~h}$. After $72 \mathrm{~h}$, the solvent was evaporated by rotary. The product was then dried and kept in refrigerator until use (Karami et al., 2019). The harvested rate of extract from plant materials was $20 \%$.

\section{Diet Preparation}

Supplemented feeds were prepared according to Vazirzadeh et al. (2017). In order to prepare the experimental diets containing essential oil, the amount of feed per week was calculated for all treatments based on 3\% body weight daily feeding. A formulated commercial feed (21 Beyza Mill Co, Shiraz, Iran) with $37 \%$ crude protein, $10 \%$ crude fat, less than $10 \%$ moisture and $4000 \mathrm{kcal} / \mathrm{kg}$ digestible energy in pellet form as basal diet was thoroughly mixed with $0.1,1$ and $10 \mathrm{~g}$ of essential oil dissolved in $30 \mathrm{~g}$ sunflower oil per $\mathrm{kg}$ of feed. For preparation of diets containing extract, $0.1,1$ and $10 \mathrm{~g}$ of extract was dissolved in $50 \mathrm{ml}$ distilled water and sprayed on $1 \mathrm{~kg}$ of food. To prevent water leaching, all diets (including control diet without any additive) were coated by $50 \mathrm{ml} / \mathrm{kg}$ of $3 \%$ gelatin solution. The prepared diets were kept at $4^{\circ} \mathrm{C}$ until use.

\section{Experimental Design}

Tilapia (45 $\pm 5 \mathrm{~g}$ ) was procured from Yazd, Iran and transported to aquaculture facilities in Shiraz University. After two weeks of acclimation, the fish were divided into 13 treatments (in triplicates each of 20 individuals). Each replicate was kept in 75L glass aquarium. Treatments were as follows: fish at control group received only basal diet containing gelatin and oil (C); Extract groups fed on diet containing extract at $0.01,0.1$ and $1 \%(\mathrm{Ex})$; Essential oil groups fed on diet containing essential oil at $0.01,0.1$ and $1 \%$ (Es). In three treatments fish fed on diet containing Essential oil and Extract in 50:50 combination at doses $0.01,0.1$ and $1 \%$ (Es+Ex). In hydrolate groups, plant hydrolate was added to aquariums at doses of 312.5, 625 and $1250 \mathrm{ppm}$ as bath treatment (Hy). In order to prevent the accumulation of hydrolate in the aquarium, after daily replacing of $50 \%$ water, half of the calculated doses were added to each aquarium.

\section{Water Quality}

The daily water change rate was $50 \%$, which was done two times in the morning and evening. The water quality parameters including dissolved oxygen $(5.5 \pm 0.4 \mathrm{~g} / \mathrm{L})$, temperature $\left(24 \pm 2^{\circ} \mathrm{C}\right)$ and $\mathrm{pH}(7.5 \pm 0.2)$ were measured and maintained at optimal ranges for O. niloticus.

\section{Growth Parameters}

Growth indices were calculated using the following formulas:

$$
\begin{aligned}
& W G(\%)=100 \times \frac{\text { Final fish weight }- \text { Initial fish weight }}{\text { Initial fish weight }} \\
& F C R=\frac{\text { Feed intake }}{\text { Weight gain }} \\
& S G R=100 \times \frac{\ln (\text { final fish weight })-\ln (\text { initial fish weight })}{\text { Experimental days }}
\end{aligned}
$$

In these formulas, $W G$ is the weight gain, FCR is the feed conversion ratio, and $S G R$ is the special growth rate.

\section{Sampling Method}

Fish were sampled by day 60 . Three fish per aquarium were taken. Fish were anesthetized with clove powder $(150 \mathrm{~g} / \mathrm{l})$ (Vazirzadeh et al., 2019) and bled using non-heparinized syringes. Sera were separated by centrifuging (K241R, Centurion Scientific Ltd England) at $5000 \mathrm{rpm}$ and $4^{\circ} \mathrm{C}$ for 20 min and kept at $-21^{\circ} \mathrm{C}$ for further analyses.

\section{Respiratory Burst Activity}

This assay was carried out following the previous method (Siwicki, 1993). Briefly, $50 \mu$ of fresh blood was mixed with 50 $\mu \mathrm{l}$ of $0.2 \%$ NBT solution and incubated for $30 \mathrm{~min}$ at $25^{\circ} \mathrm{C}$. Then, $50 \mu \mathrm{l}$ of solution was mixed with $1 \mathrm{ml}$ of dimethylformamide and centrifuged at $12000 \mathrm{rpm}$ for 15 minutes. The absorbance of the supernatant was read at $540 \mathrm{~nm}$ using a spectrophotometer (PG Instruments Ltd, UK). Dimethylformamide was used as blank.

\section{Lysozyme Activity}

The levels of lysozyme activity were measured using a turbidiometric assay according to Ross et al (Neil et al. 2000) with minor modification. To prepare a bacterium suspension, $9 \mathrm{mg}$ of Micrococcus luteus cell wall were dissolved in $30 \mathrm{ml}$ phosphate buffer $(\mathrm{pH}=7.4)$. Then $90 \mu \mathrm{l}$ of this suspension were mixed with $10 \mu \mathrm{l}$ of fish serum and the absorbance was read at $450 \mathrm{~nm}$ using microplate reader (Bio Tek TS 800, USA) at times 0 and 10. One unit of activity was defined as $0.001 \mathrm{~min}^{-1}$ decrease in the mixture absorbance at $450 \mathrm{~nm}$.

\section{Blood Biochemical Parameters}

Triglyceride (TG), cholesterol (Chol), alkaline phosphatase (ALP), alanine aminotransferase (SGOT), aspartate aminotransferase (SGPT), total protein (Tpr), and albumin (alb) levels were measured using commercial kits (Pars Azmun, Iran) following the manufacturer's protocol. The serum globulin (Glb) was estimated by subtracting the amounts of protein and albumin. 


\section{Statistical Analyses}

This experiment was carried out as a completely randomized design. Data were analyzed by One- way ANOVA in SAS 9.1.4 software (SAS institute, NC). Before ANOVA analysis, the normality of data was checked by Shapiro-Wilk test. The mean squares of the treatments were compared by Tukey post-hoc test at the significant level of $\mathrm{P}<0.05$. Data were presented as mean \pm pooled standard error of mean (SEM).

\section{Results}

\section{Growth Parameters}

Table 1 shows the growth parameters of Nile tilapia after 60 days of treatment with different derivatives of $O$. decumbens. Although, there were some differences among treatments, the differences were not significant at $\mathrm{P} \leq 0.05$ for $\mathrm{WG} \%$, SGR and FCR.

Table 1. Differences of growth parameters in Nile tilapia received different doses of essential oil, extract and hydrolate of O. decumbens

\begin{tabular}{|c|c|c|c|}
\hline \multirow{2}{*}{ Treatments } & \multirow{2}{*}{ Weight gain\% } & \multicolumn{2}{|c|}{ Growth parameters } \\
\hline & & SGR\% & FCR \\
\hline Control & 86.18 & 3.08 & 0.97 \\
\hline \multicolumn{4}{|l|}{ Essential oil } \\
\hline $0.01 \%$ & 83.14 & 3.02 & 0.81 \\
\hline $0.1 \%$ & 106.40 & 3.62 & 0.77 \\
\hline $1 \%$ & 90.88 & 3.23 & 0.85 \\
\hline \multicolumn{4}{|l|}{ Extract } \\
\hline $0.01 \%$ & 139.88 & 4.35 & 0.71 \\
\hline $0.1 \%$ & 89.66 & 3.19 & 0.87 \\
\hline $1 \%$ & 122.71 & 3.96 & 0.77 \\
\hline \multicolumn{4}{|c|}{ Extract+ Essential oil } \\
\hline $0.01 \%$ & 75.00 & 2.78 & 0.82 \\
\hline $0.1 \%$ & 133.37 & 4.23 & 0.60 \\
\hline $1 \%$ & 122.99 & 4.01 & 0.76 \\
\hline \multicolumn{4}{|l|}{ Hydrolate } \\
\hline $312.5 \mathrm{ppm}$ & 98.35 & 3.42 & 0.73 \\
\hline $625 \mathrm{ppm}$ & 86.78 & 3.09 & 0.88 \\
\hline 1250 ppm & 79.19 & 2.92 & 0.90 \\
\hline P-Value & 0.1119 & 0.1179 & 0.3356 \\
\hline Pooled sem & 14.89 & 0.36 & 0.08 \\
\hline
\end{tabular}

Note: Data are presented as means \pm pooled S.E.M.

\section{Immunological Parameters}

\section{Respiratory Burst Activity}

The extract $1 \%$ group showed the highest level of respiratory burst activity, which was significantly different from control group at $\mathrm{P} \leq 0.05$ (Figure 1).

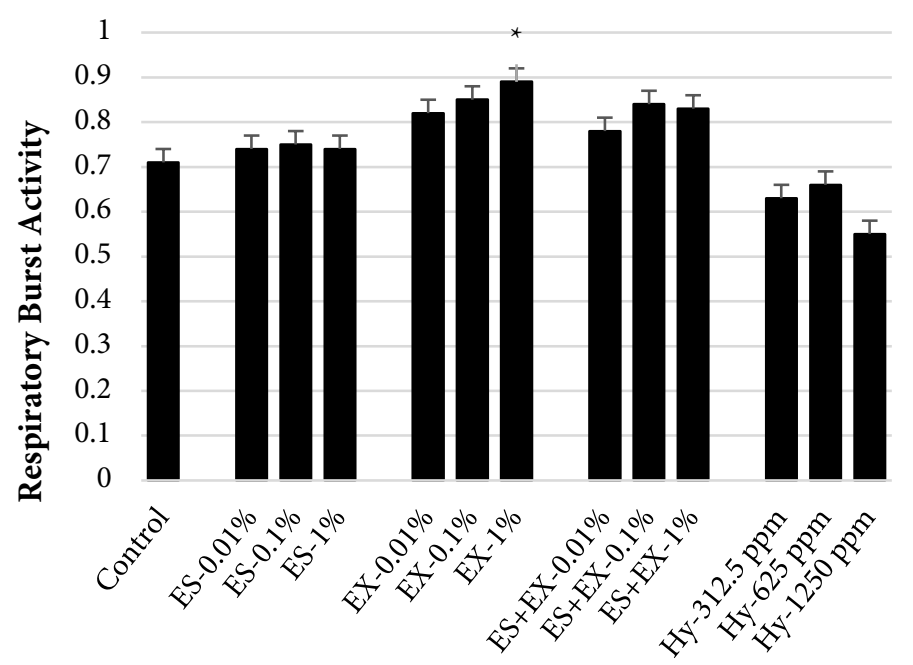

Figure 1. The effects of treatments (receiving different doses of essential oil, extract and hydrolate of Oliveria decumbens) on the respiratory burst activity (OD at $540 \mathrm{~nm}$ ) in Nile tilapia. Treatments indicated by ${ }^{*}$ are significantly different from control group at $\mathrm{p} \leq 0.05$. Es: essential oil; Ex: extract; Es + Ex; combination of essential oil and extract; Hy: hydrolate.

\section{Lysozyme Activity}

Different treatments significantly affected the lysozyme level in fish $(\mathrm{P} \leq 0.05)$. The level of lysozyme in fish received extract and essential oil or their combinations were significantly higher than that in control group (Figure 2).

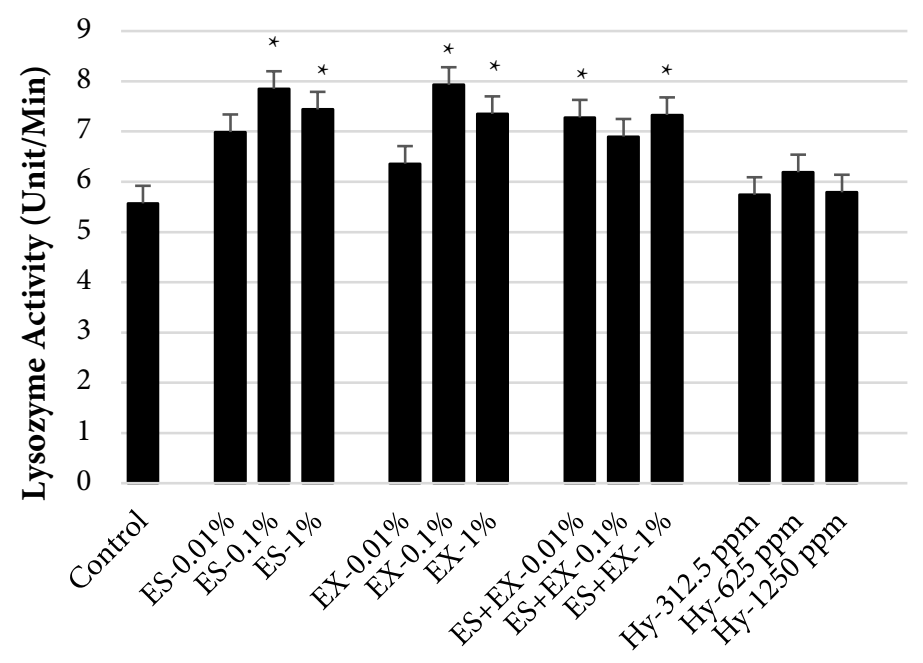

Figure 2. The effects of treatments (receiving different doses of essential oil, extract and hydrolate of Oliveria decumbens) on the lysozyme levels (U/min) in Nile tilapia. Treatments indicated by ${ }^{*}$ are significantly different from control group at $\mathrm{p} \leq 0.05$. Es: essential oil; Ex: extract; Es +Ex; combination of essential oil and extract; Hy: hydrolate. 


\section{Total Ptotein (Tpr), Albumin (Alb) and Globulin (Glb)}

The levels of Tpr, Alb and Glb are depicted in Figure 3. The highest level of $\operatorname{Tpr}(3.75 \mathrm{~g} / \mathrm{dl})$ was reported in hydrolate 312.5 ppm group, which was significantly different from control group. No significant differences were observed among treatments in case of Alb level. But, based on our findings, the effects of treatment were significant on the Glb levels $(\mathrm{P} \leq 0.05)$. The extract $1 \%$ receiving group had the highest level $(2.7 \mathrm{~g} / \mathrm{dl})$ which was significantly higher than the control group (1.65 $\mathrm{g} / \mathrm{dl})$.
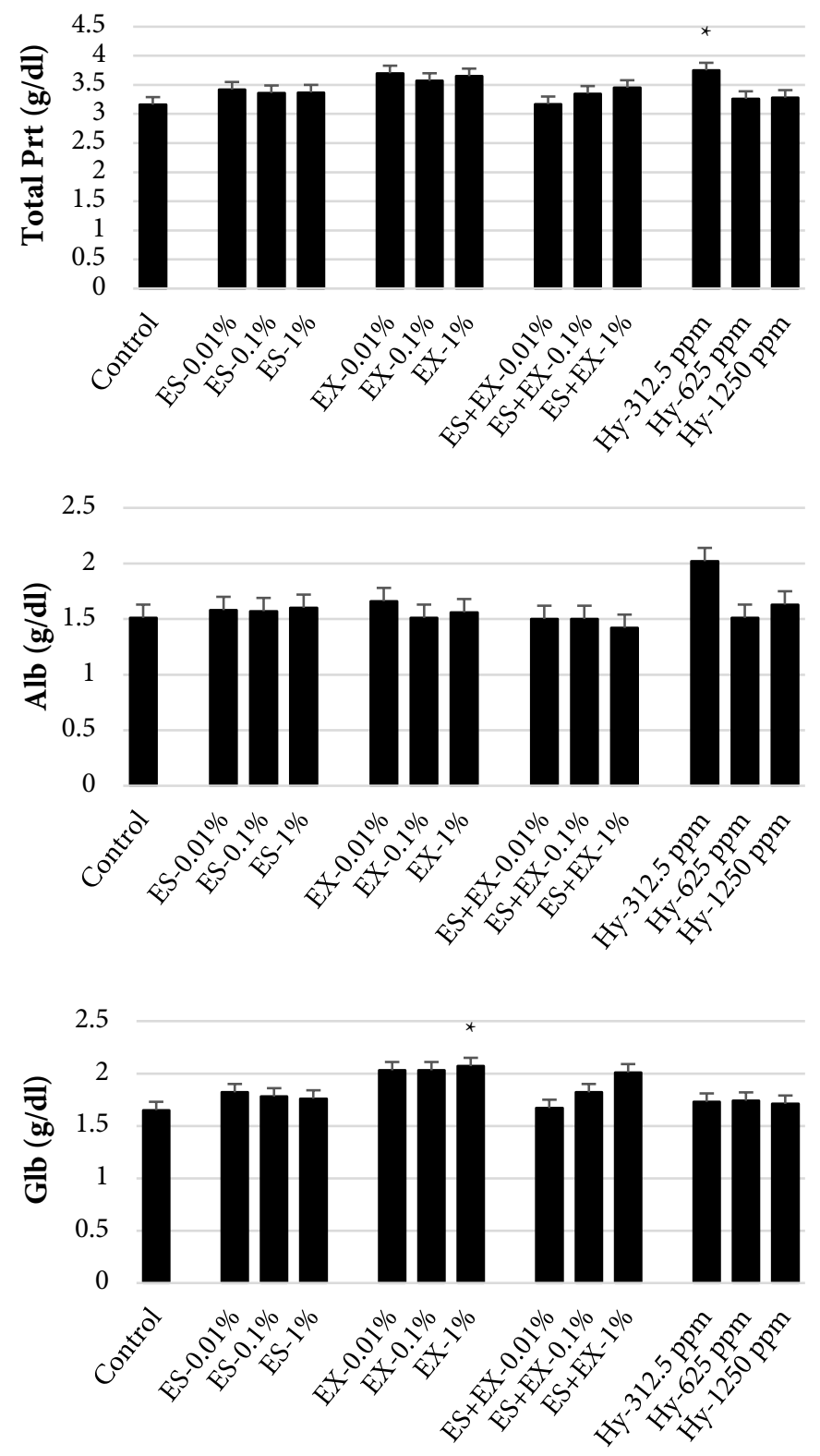

Figure 3. The effects of treatments (receiving different doses of essential oil, extract and hydrolate of Oliveria decumbens) on the serum total protein $(\mathrm{g} / \mathrm{dl})$, albumin $(\mathrm{g} / \mathrm{dl})$ and globulin levels $(\mathrm{g} / \mathrm{dl})$ in Nile tilapia. In case of serum total protein and globulin, treatments indicate by ${ }^{*}$ symbol are significantly different from control group at $\mathrm{P}<0.05$. No significant differences were observed for serum albumin levels. Es: essential oil; Ex: extract; Es +Ex; combination of essential oil and extract; Hy: hydrolate.

\section{Triglyceride (TG) and Cholesterol (Chol)}

The levels of TG and Chol are presented in Figure 4. Although, some fluctuations were observed among treatments, due to intra group individual variations, the differences were not significant at $\mathrm{P} \leq 0.05$.
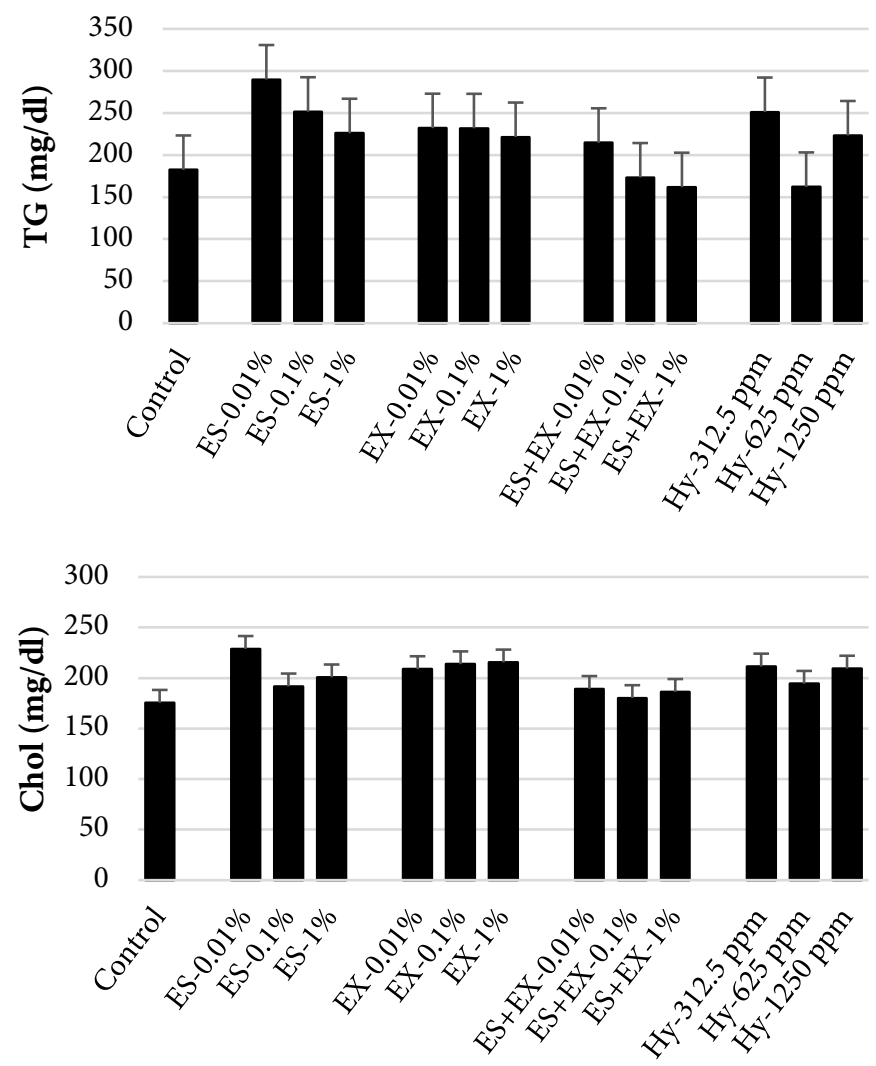

Figure 4. The effects of treatments (receiving different doses of essential oil, extract and hydrolate of Oliveria decumbens) on the serum triglyceride $(\mathrm{g} / \mathrm{dl})$ and cholesterol $(\mathrm{g} / \mathrm{dl})$ in Nile tilapia. No significant differences were observed among treatments ( $p>0.05)$. Es: essential oil; Ex: extract; Es +Ex; combination of essential oil and extract; Hy: hydrolate.

Aspartate Aminotransferase (SGOT), Alanine Aminotransferase (SGPT) and Alkaline Phosphatase (Alp)

Figure 5 shows the results of changes in SGOT, SGPT and Alp levels in fish received different derivatives of O. decumbens. No significant differences were observed in either SGOT and SGPT values or Alp levels.

\section{Discussion}

Recently use of medicinal plants has emerged as an appropriate alternative to control diseases in aquatic organisms (Awad and Awaad, 2017; Wang et al., 2017) due to the adverse effects of chemicals and drugs used in aquaculture on fish as well as on the environment and human health. 

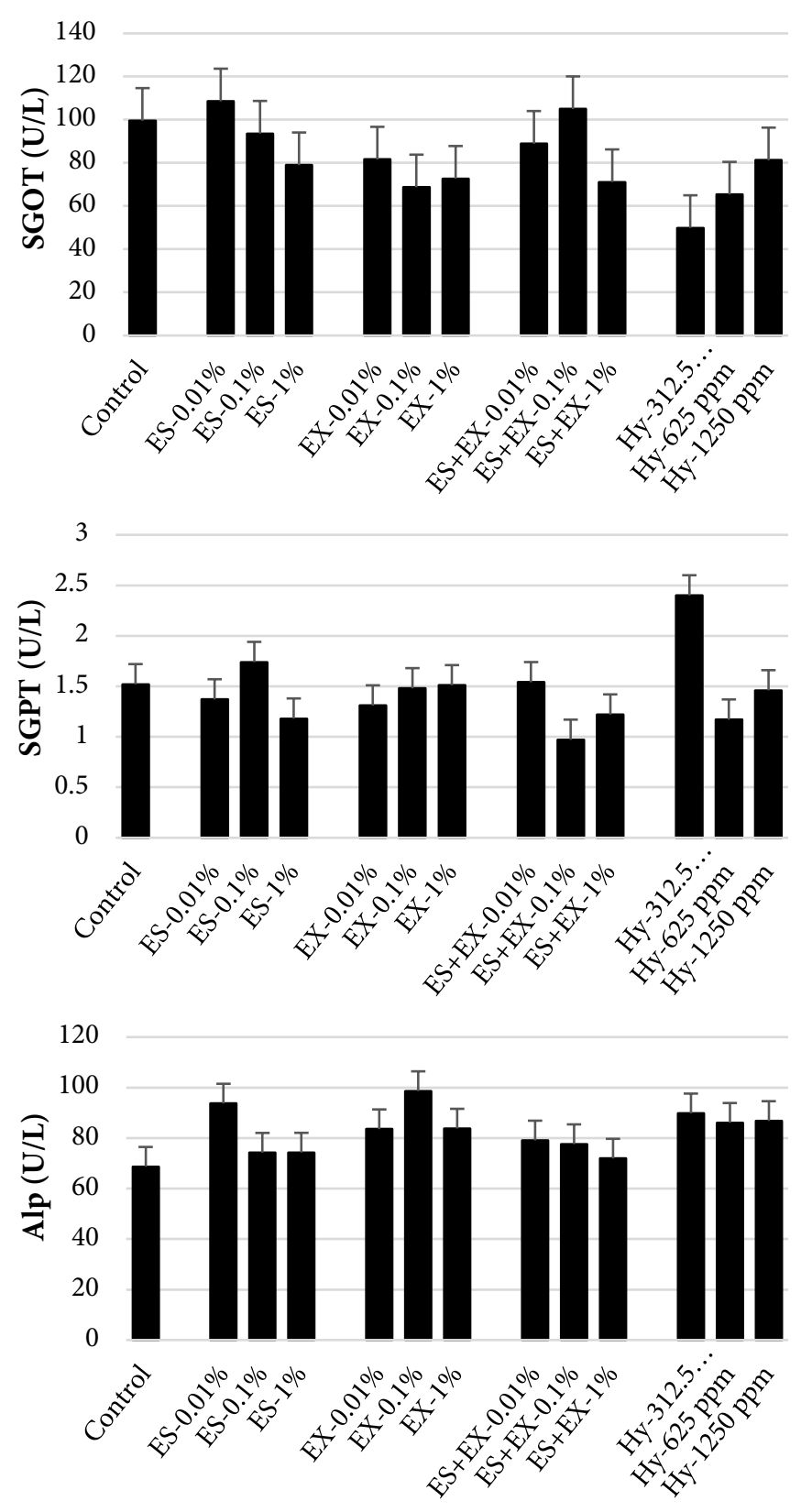

Figure 5. The effects of treatments (receiving different doses of essential oil, extract and hydrolate of Oliveria decumbens) on the serum alanine aminotransferase (U/l), aspartate aminotransferase $(\mathrm{U} / \mathrm{l})$ and alkaline phosphatase (U/l) levels in Nile tilapia. No significant differences were observed among treatments $(\mathrm{p}>0.05)$. Es: essential oil; Ex: extract; Es +Ex; combination of essential oil and extract; Hy: hydrolate.

Extract, essential oil and hydrolate are the most common derivatives of medicinal plant used as traditional and green antimicrobial and immunomodulatory agents in humans and animals including fishes ((Esmaeili et al., 2018; Karami et al., 2019). In previous studies, extract and essential oils of a wide variety of plants were effectively used to improve immune responses in fishes (Ringø et al., 2012; Reverter et al., 2014). To the best of our knowledge, there was no study on the immunostimulatory effects of hydrolate of any plants in aquaculture. Therefore, the effects of hydrolate and two other common derivatives (essential oil and extract) of $O$. decumbens were evaluated on innate immunity of Nile tilapia in this study. The results of current study showed that treatment with extract, essential oil and hydrolate of $O$. decumbens had no adverse effects on the growth parameters of Nile tilapia. Similar finding has been reported in the use of different concentrations of Myristica fragrans on growth of juvenile greasy grouper (Epinephelus tauvina) (Sivaram et al., 2004). It has been reported that diets containing propolis did not affect the growth rate of gilthead seabream, Sparus aurata (Cuesta et al., 2005). Also, Mucor circinelloides diet did not make a difference in the growth of gilthead seabream in six weeks (Rodriguez et al., 2004). In another study, plantain (Plantago asiatica, fish mint (Houttuynia cordata) and field mint (Mentha haplocalyx) did not make a significant difference in growth factors of cobia (Rachycentron canadum) in comparison with that of the control group (Wu et al., 2016). Based on the present study, $O$. decumbens had no negative effects on growth parameters in fish. Therefore, O. decumbens can be safely used in tilapia aquaculture.

In this study, the high level of respiratory burst activity in the $O$. decumbens extract was indicative of innate immune response stimulation. It is believed that the respiratory burst activity inhibits pathogenic activity through producing toxic reactive oxygen species (Kumar et al., 2013). In line with our results, the respiratory burst activity increased in Nile tilapia fed with Viscum album coloratum plant extract (Park and Choi, 2012). Confirming to the results of our current study, an increase in respiratory burst activity was reported by diets containing 5 and 10\% mangrove Rhizophora apiculata extract in clownfish Amphiprion sebae (Dhayanithi et al., 2015). Also, the extract of devil-pepper Rauvolfia tetraphylla at 5 and $10 \%$ resulted in increased respiratory burst activity in carp, Labeo rohita (Yogeshwari et al., 2015). Similar results were reported in the rainbow trout (Oncorhynchus mykiss) fed on 0.1 and 0.5 $\mathrm{g} / \mathrm{kg}$ Nigella sativa (Celik Altunoglu et al., 2017). Overall, there was no direct positive correlation between the effects of immunostimulants and their doses. A higher dose of an immune stimulant may lead to the immune system suppression and therefore, deterioration of fish health status (Divyagnaneswari et al., 2007). Thus, it is likely that $1250 \mathrm{ppm}$ dose of hydrolate has a negative effect on the immune system, and lowered the respiratory burst activity. Our finding was in line with the studies by (Giri et al., 2015) and (Gabriel et al., 2015) who reported the suppression of the immune system by high doses of aloe vera (4\%) and Pedalium murex medicinal plant with the diet in several fishes. 
As an important enzyme to cope with pathogens such as viruses, bacteria, and parasites, lysozyme was measured in tilapia in this study (Saurabh and Sahoo, 2008). It is well understood that the level of lysozyme elevates in serum during the infections (Celik Altunoglu et al., 2017). Lysozyme fights against bacteria by lysing their cell walls. According to the results of this present study, supplementing feed with extract and essential oil of $O$. decumbens led to higher levels of serum lysozyme in comparison to fish in control group. The increment in blood lysozyme levels is associated with a higher phagocytosis activity of leukocytes (Kumar et al. 2013). Altogether, these results are in line with previous findings suggesting the effectiveness of herbal immunostimulants in enhancement of blood lysozyme levels (Zhou et al., 2012; Kumar et al., 2013; Zanuzzo et al., 2015; Celik Altunoglu et al., 2017).

Total serum protein is one of the major factors in the innate immune responses of fish (Acar et al., 2015) and they are divided into albumin and globulin groups. Within the latter group, gamma globulins are the source of nearly all immunologically active proteins in the blood (Kumar et al., 2013). Increasing levels of protein, albumin, and globulin in the serum should lead to a stronger immune response in fish (Gabriel et al., 2015). Nile tilapia fed on O. decumbens for 60 days had the lowest level of protein in the control group and the highest for the hydrolate group at dose of $312.5 \mathrm{ppm}$. Several studies have reported the increase in serum total protein levels in fish after receiving herbal immunostimulants (Dügenci et al., 2003; Bilen et al., 2011; Awad and Awaad 2017). For example, feeding smoke tree Cotinus coggyria for 9 weeks increased the serum protein levels in rainbow trout compared to control group (Bilen et al., 2011). Also, the extract of loquat Eriobotrya japonica at doses of 1 and $2 \%$ increased serum total protein levels in longtooth grouper (Epinephelus bruneus) at the second week of treatment (Harikrishnan et al., 2011). Albumin is an essential component for maintaining osmotic pressure, the robustness of the immune system, and as a carrier in plasma (Talpur and Ikhwanuddin, 2012). In the present study, no significant differences were observed among serum albumin levels of treatments. Similar to our result, the use of lemon citrus limon essential oil in O. mossambicus did not have any effect on serum albumin levels (Baba et al., 2016). Also, common nettle Urtica dioica urtica powder at doses of 3, 6 and 12\% did not alter the serum albumin levels in beluga sturgeon (Huso huso) after 8 weeks (Binaii et al., 2014). Also, in our previous study, the essential oil of Ducrosia anethifolia did not affect the amount of albumin in rainbow trout received three doses of $0.001,0.01$ and $0.1 \%$ (Vazirzadeh et al., 2017). Globulins are important proteins that play an essential role in the innate immune response against stress and infection (Talpur and Ikhwanuddin, 2012; Vazirzadeh et al., 2017). It also leads to a stronger immune response in fish (Binaii et al., 2014) and is essential for the stability of the immune system (Kumar et al., 2013). The results of this study showed an increase in globulin levels in $1 \%$ extract treatment compared to control group. In line with this study, an increase in serum globulin levels in rainbow trout has been reported after feeding common nettle (Binaii et al., 2014), fennel flower Nigella sativa and common nettle (Awad et al., 2013). Also, Serum globulin increased in E. bruneus received 1 and $2 \%$ of loquat extract, compared to control group (Harikrishnan et al., 2010).

Our previous study (Vazirzadeh et al., 2019) and earlier studies on the active compositions of $O$. decumbens by GC-MS spectrometry analysis showed $\gamma$-terpinene, myristicin, thymol, $\rho$-cymene and carvacrol as the most frequent compounds of plant (Amin et al., 2005; Hajimehdipoor et al., 2010; Esmaeili et al., 2018). All these compounds have significant immunostimulatory and antimicrobial activities which justify the immunostimulatory results obtained by present study. Although, the mechanism of immunostimulatory effects of plants have not been clearly discussed yet, it is believed that plants improve the innate immune system of fish via strengthening cellular and molecular defense system (Harikrishnan et al., 2010). Also, our previous study showed a remarkable in vitro antibacterial activity for essential oil and a significant in vivo resistance following challenge by Streptococcosis iniae in Nile tilapia for hydrolate at $312.5 \mathrm{ppm}$ of O. decumbens (Vazirzadeh et al., 2019).

The results of this current study showed no significant differences in the levels of TG, Chol, and ALP in Nile tilapia fed on diets containing different compounds of O. decumbens. TG, Chol and ALP are main intravascular health indicators in vertebrates (Chatzifotis et al., 2011). Among them, Chol is one of the main components of cell membranes and precursors for steroid hormones, and bile acids and TG are stearic compounds of glycerol and fatty acids which have an important role in detecting and tracking lipoprotein disorders (Dadras et al., 2016). Measurement of ALP is an indicator for diagnosis of diseases and problems in bone, liver and gallbladder. High levels of ALP can be associated with disease (Wang and Sun 2016). Comparable to the results of this study, there are reports corroborating innocuousness of different herbal compounds on the level of aforementioned factors (Acar et al., 2015; Yeganeh et al., 2015; Baba et al. 2016). Thus, O. decumbens has no negative effects on liver and heart tissues and cardiovascular activity. The increment of the parameters over times have also no concerns because all fall in the normal range for fish under experimental condition and raise of the parameters relates to 
the age and weight of fish (Binaii et al., 2014; Reyes-Becerril et al., 2014).

SGOT and SGPT enzymes are important indicators for the diagnosis of hepatotoxicity in the pancreas (Dadras et al., 2016). Based on the results of this study, there was no significant difference in the level of hepatic enzyme of SGOT and SGPT in different treatments. Therefore, the findings indicated that the O. decumbens does not contain detectable toxic compounds with negative effects on the liver tissue and consequently on the activity of hepatic enzymes as confirmed by GC-Mass spectrometry analysis. In line with our results, in beluga sturgeon, SGOT and SGPT levels were not affected by the different levels of the nettle as immunostimulant (Binaii et al., 2014). One concern in using herbs or their derivative is the possibility of liver and tissue damages due to activity of toxic compounds (Dadras et al., 2016). For example, a study by (Vasudeva Rao et al., 2006) reported an increase in liver enzymes of Labeo rohita treated with diet containing Achyranthes aspera - an Indian medicinal plant- which indicates a negative effect of the plant on fish liver tissue. Therefore, evaluation of liver enzymes as indicators of fish hepatic health is necessary to ensure further about safety of using herbal compounds.

\section{Conclusion}

Overall, the results of this study showed that different derivatives of $O$. decumbens in the forms of essential oil, extract and hydrolate improved innate immune parameters status without any negative effects on growth and biochemical parameters. The possibility to use hydrolate form of herbal compounds as an immunostimulant in fish was also confirmed for the first time in this study. The use of different compounds of $O$. decumbens as an environment-friendly immunostimulant to improve the innate immune system and to cope with diseases is recommended in Nile tilapia aquaculture.

\section{Acknowledgements}

This study was financially supported by Shiraz University Council of Research (Grant No 96GCU1M215785). We are also grateful to Dr. Farhadi, for his valuable comments on the English improvement of the manuscript.

\section{Availability of Data and Materials}

The data that support the findings of this study are available on request from the corresponding author. The data are not publicly available due to privacy or ethical restrictions.

\section{Compliance with Ethical Standards}

\section{Authors' Contributions}

AV conceived and designed the experiment. SJ and AV prepared the diets, performed the trial and collected the experiments data. SJ and AV carried out all immunological and other required analyses. MA carried out biochemical analyses. AK provided herbal composition analyses. AV and SJ analyzed and interpret the data. AV wrote the draft of the manuscript. All authors critically reviewed the manuscript for intellectual content and gave final approval for the version to be published.

\section{Conflict of Interest}

The authors declare that there is no conflict of interest.

\section{Ethical Approval}

The experiments and fish handling were conducted based on the Institutional Animal Care and Ethics Committee of the Shiraz University regulations with minimal suffering of experimental animals.

\section{References}

Acar, Ü., Kesbiç, O. S., Yılmaz, S., Gültepe, N. \& Türker, A. (2015). Evaluation of the effects of essential oil extracted from sweet orange peel (Citrus sinensis) on growth rate of tilapia (Oreochromis mossambicus) and possible disease resistance against Streptococcus iniae. Aquaculture,

437:

$282-286$

https://doi.org/10.1016/j.aquaculture.2014.12.015

Adel, M., Abedian Amiri, A., Zorriehzahra, J., Nematolahi, A. \& Esteban, M. Á. (2015). Effects of dietary peppermint (Mentha piperita) on growth performance, chemical body composition and hematological and immune parameters of fry Caspian white fish (Rutilus frisii kutum). Fish \& Shellfish Immunology, 45(2): 841-847. https://doi.org/10.1016/j.fsi.2015.06.010

Alizadeh Behbahani, B., Tabatabaei Yazdi, F., Vasiee, A. \& Mortazavi, S. A. (2018). Oliveria decumbens essential oil: Chemical compositions and antimicrobial activity against the growth of some clinical and standard strains causing infection. Microbial Pathogenesis, 114: 449-452. https://doi.org/10.1016/j.micpath.2017.12.033

Amin, G., Sourmaghi, M. H. S., Zahedi, M., Khanavi, M. \& Samadi, N. (2005). Essential oil composition and antimicrobial activity of Oliveria decumbens. Fitoterapia, $\quad$ 76(7): 704-707. 
Andrade, J. I. A., Jerônimo, G. T., Brasil, E. M., Nunez, C. V., Gonçalves, E. L. T., Ruiz, M. L., \& Martins, M. L. (2016). Efficacy of seed extract of Bixa orellana against monogenean gill parasites and physiological aspects of Colossoma macropomum after bath treatment. Aquaculture, 462: 40-46. https://doi.org/10.1016/j.aquaculture.2016.04.024

Ardó, L., Yin, G., Xu, P., Váradi, L., Szigeti, G., Jeney, Z. \& Jeney, G. (2008). Chinese herbs (Astragalus membranaceus and Lonicera japonica) and boron enhance the non-specific immune response of Nile tilapia (Oreochromis niloticus) and resistance against Aeromonas hydrophila. Aquaculture, 275(1-4): 26-33. https://doi.org/10.1016/j.aquaculture.2007.12.022

Awad, E., Austin, D. \& Lyndon, A. R. (2013). Effect of black cumin seed oil (Nigella sativa) and nettle extract (Quercetin) on enhancement of immunity in rainbow trout, Oncorhynchus mykiss (Walbaum). Aquaculture, 388-391:

193-197.

https://doi.org/10.1016/j.aquaculture.2013.01.008

Awad, E. \& Awaad, A. (2017). Role of medicinal plants on growth performance and immune status in fish. Fish \& Shellfish Immunology, 67: 40-54. https://doi.org/10.1016/j.fsi.2017.05.034

Baba, E., Acar, Ü., Öntaş, C., Kesbiç, O. S. \& Yılmaz, S. (2016). Evaluation of Citrus limon peels essential oil on growth performance, immune response of Mozambique tilapia Oreochromis mossambicus challenged with Edwardsiella tarda. Aquaculture, 465: 13-18. https://doi.org/10.1016/j.aquaculture.2016.08.023

Bilen, S., Bulut, M. \& Bilen, A. M. (2011). Immunostimulant effects of Cotinus coggyria on rainbow trout (Oncorhynchus mykiss). Fish \& Shellfish Immunology, 30(2): 451-455. https://doi.org/10.1016/j.fsi.2010.12.013

Binaii, M., Ghiasi, M., Farabi, S. M. V., Pourgholam, R., Fazli, H., Safari, R., Alavi, S. E., Taghavi, M. J. \& Bankehsaz, Z. (2014). Biochemical and hemato-immunological parameters in juvenile beluga (Huso huso) following the diet supplemented with nettle (Urtica dioica). Fish \& Shellfish Immunology, 36(1): 46-51. https://doi.org/10.1016/j.fsi.2013.10.001

Brum, A., Pereira, S. A., Owatari, M. S., Chagas, E. C., Chaves, F. C. M., Mouriño, J. L. P. \& Martins, M. L. (2017). Effect of dietary essential oils of clove basil and ginger on Nile tilapia (Oreochromis niloticus) following challenge with Streptococcus agalactiae. Aquaculture, 468: 235-243. https://doi.org/10.1016/j.aquaculture.2016.10.020
Celik Altunoglu, Y., Bilen, S., Ulu, F. \& Biswas, G. (2017). Immune responses to methanolic extract of black cumin (Nigella sativa) in rainbow trout (Oncorhynchus mykiss). Fish \& Shellfish Immunology, 67: 103-109. https://doi.org/10.1016/j.fsi.2017.06.002

Chatzifotis, S., Papadaki, M., Despoti, S., Roufidou, C. \& Antonopoulou, E. (2011). Effect of starvation and refeeding on reproductive indices, body weight, plasma metabolites and oxidative enzymes of sea bass (Dicentrarchus labrax). Aquaculture, 316(1): 53-59. https://doi.org/10.1016/j.aquaculture.2011.02.044

Cuesta, A., Rodríguez, A., Esteban, M. Á. \& Meseguer, J. (2005). In vivo effects of propolis, a honeybee product, on gilthead seabream innate immune responses. Fish \& Shellfish Immunology, $18(1)$ : $\quad$ 71-80. https://doi.org/10.1016/j.fsi.2004.06.002

Cunha, J. A., de Ávila Scheeren, C., Fausto, V. P., de Melo, L. D. W., Henneman, B., Frizzo, C. P., de Almeida Vaucher, R., de Vargas, A. C. \& Baldisserotto, B. (2018). The antibacterial and physiological effects of pure and nanoencapsulated Origanum majorana essential oil on fish infected with Aeromonas hydrophila. Microbial Pathogenesis,

124:

116-121. https://doi.org/10.1016/j.micpath.2018.08.040

Dadras, H., Hayatbakhsh, M. R., Shelton, W. L. \& Golpour, A. (2016). Effects of dietary administration of Rose hip and Safflower on growth performance, haematological, biochemical parameters and innate immune response of Beluga, Huso huso (Linnaeus, 1758). Fish \& Shellfish Immunology, 59: 109-114. https://doi.org/10.1016/j.fsi.2016.10.033

Dhayanithi, N. B., Ajith Kumar, T. T., Arockiaraj, J., Balasundaram, C. \& Harikrishnan, R. (2015). Dietary supplementation of Avicennia marina extract on immune protection and disease resistance in Amphiprion sebae against Vibrio alginolyticus. Fish \& Shellfish Immunology, 45(1): 52-58. https://doi.org/10.1016/j.fsi.2015.02.018

Divyagnaneswari, M., Christybapita, D. \& Michael, R. D. (2007). Enhancement of nonspecific immunity and disease resistance in Oreochromis mossambicus by Solanum trilobatum leaf fractions. Fish \& Shellfish Immunology, $\quad \mathbf{2 3 ( 2 ) :}$ 249-259. https://doi.org/10.1016/j.fsi.2006.09.015

Dügenci, S. K., Arda, N. \& Candan, A. (2003). Some medicinal plants as immunostimulant for fish. Journal of Ethnopharmacology, $\quad \mathbf{8 8}(1)$ : $99-106$. https://doi.org/10.1016/S0378-8741(03)00182-X 
Esmaeili, H., Karami, A. \& Maggi, F. (2018). Essential oil composition, total phenolic and flavonoids contents, and antioxidant activity of Oliveria decumbens Vent. (Apiaceae) at different phenological stages. Journal of Cleaner Production, 198: 91-95. https://doi.org/10.1016/j.jclepro.2018.07.029

Gabriel, N. N., Qiang, J., He, J., Ma, X. Y., Kpundeh, M. D. \& $\mathrm{Xu}, \mathrm{P}$. (2015). Dietary Aloe vera supplementation on growth performance, some haemato-biochemical parameters and disease resistance against Streptococcus iniae in tilapia (GIFT). Fish \& Shellfish Immunology, 44(2): 504-514. https://doi.org/10.1016/j.fsi.2015.03.002

Giri, S. S., Sen, S. S., Chi, C., Kim, H. J., Yun, S., Park, S. C. \& Sukumaran, V. (2015). Effect of guava leaves on the growth performance and cytokine gene expression of Labeo rohita and its susceptibility to Aeromonas hydrophila infection. Fish \& Shellfish Immunology, 46(2): 217-224. https://doi.org/10.1016/j.fsi.2015.05.051

Grammer, G. L., Slack, W. T., Peterson, M. S. \& Dugo, M. A. (2012). Nile tilapia Oreochromis niloticus (Linnaeus, 1758) establishment in temperate Mississippi, USA: Multi-year survival confirmed by otolith ages. Aquatic Invasions, $\quad 7(3)$ : 367-376. https://doi.org/10.3391/ai.2012.7.3.008

Hajimehdipoor, H., Samadi, N., Mozaffarian, V., Rahimifard, N., Shoeibi, S. \& Pirali Hamedani, M. (2010). Chemical composition and antimicrobial activity of Oliveria decumbens volatile oil from west of Iran. Journal of Medicinal Plants, 1(33): 39-44.

Harikrishnan, R., Balasundaram, C. \& Heo, M.-S. (2010). Herbal supplementation diets on hematology and innate immunity in goldfish against Aeromonas hydrophila. Fish \& Shellfish Immunology, 28(2): 354-361. https://doi.org/10.1016/j.fsi.2009.11.013

Harikrishnan, R., Balasundaram, C. \& Heo, M.-S. (2011). Impact of plant products on innate and adaptive immune system of cultured finfish and shellfish. Aquaculture, $\quad 317(1-4)$ : 1-15. https://doi.org/10.1016/j.aquaculture.2011.03.039

Harikrishnan, R., Balasundaram, C., Kim, M.-C., Kim, J.-S., Han, Y.-J. \& Heo, M.-S. (2009). Innate immune response and disease resistance in Carassius auratus by triherbal solvent extracts. Fish \& Shellfish Immunology, 27(3): 508-515. https://doi.org/10.1016/j.fsi.2009.07.004
Karami, A., Kavoosi, G. \& Maggi, F. (2019). The emulsion made with essential oil and aromatic water from Oliveria decumbens protects murine macrophages from LPSinduced oxidation and exerts relevant radical scavenging activities. Biocatalysis and Agricultural Biotechnology,

17:

538-544 https://doi.org/10.1016/j.bcab.2019.01.015

Kumar, S., Raman, R. P., Pandey, P. K., Mohanty, S., Kumar, A. \& Kumar, K. (2013). Effect of orally administered azadirachtin on non-specific immune parameters of goldfish Carassius auratus (Linn. 1758) and resistance against Aeromonas hydrophila. Fish \& Shellfish Immunology, 34(2): 564-573. https://doi.org/10.1016/j.fsi.2012.11.038

Neil, W. R., Kara, J. F., Anping, W., John, F. B. \& Stewart, C. J. (2000). Changes in hydrolytic enzyme activities of native Atlantic salmon Salmo salar skin mucus due to infection with the salmon louse Lepeophtheirus salmonis and cortisol implantation. Diseases of Aquatic Organisms, 41(1): 43-51. https://doi.org/10.3354/DAO041043

Park, K.-H. \& Choi, S.-H. (2012). The effect of mistletoe, Viscum album coloratum, extract on innate immune response of Nile tilapia (Oreochromis niloticus). Fish \& Shellfish Immunology, 32(6): 1016-1021. https://doi.org/10.1016/j.fsi.2012.02.023

Reverter, M., Bontemps, N., Lecchini, D., Banaigs, B. \& Sasal, P. (2014). Use of plant extracts in fish aquaculture as an alternative to chemotherapy: Current status and future perspectives. Aquaculture, 433: 50-61. https://doi.org/10.1016/j.aquaculture.2014.05.048

Reyes-Becerril, M., Angulo, C., Estrada, N., Murillo, Y. \& Ascencio-Valle, F. (2014). Dietary administration of microalgae alone or supplemented with Lactobacillus sakei affects immune response and intestinal morphology of Pacific red snapper (Lutjanus peru). Fish \& Shellfish Immunology, 40(1): 208-216. https://doi.org/10.1016/j.fsi.2014.06.032

Ringø, E., Olsen, R. E., Vecino, J. L. G., Wadsworth, S. \& Song, S. K. (2012). Use of immunostimulants and nucleotides in aquaculture: A review. Journal of Marine Science: Research \& Development, 1: 1-22. https://doi.org/10.4172/2155-9910.1000104 
Rodríguez, A., Cuesta, A., Esteban, M. Á. \& Meseguer, J. (2004). The effect of dietary administration of the fungus Mucor circinelloides on non-specific immune responses of gilthead seabream. Fish \& Shellfish Immunology, 16(2): 241-249. https://doi.org/10.1016/S1050-4648(03)00082$\underline{2}$

Safari, R., Hoseinifar, S. H., Nejadmoghadam, S. \& Jafar, A. (2016). Transciptomic study of mucosal immune, antioxidant and growth related genes and non-specific immune response of common carp (Cyprinus carpio) fed dietary Ferula (Ferula assafoetida). Fish \& Shellfish Immunology, 55: 242-248. https://doi.org/10.1016/j.fsi.2016.05.038

Sakai, M. (1999). Current research status of fish immunostimulants. Aquaculture, 172(1-2): 63-92. https://doi.org/10.1016/S0044-8486(98)00436-0

Saurabh, S. \& Sahoo, P. K. (2008). Lysozyme: an important defence molecule of fish innate immune system. Aquaculture Research, 39(3): 223-239. https://doi.org/10.1111/j.1365-2109.2007.01883

Sivaram, V., Babu, M. M., Immanuel, G., Murugadass, S., Citarasu, T. \& Marian, M. P. (2004). Growth and immune response of juvenile greasy groupers (Epinephelus tauvina) fed with herbal antibacterial active principle supplemented diets against Vibrio harveyi infections. Aquaculture, 237(1): 9-20. https://doi.org/10.1016/j.aquaculture.2004.03.014

Siwicki, A. K. (1993). Nonspecific defense mechanisms assay in fish. II. Potential killing activity of neutrophils and macrophages, lysozyme activity in serum and organs and total immunoglobulin (Ig) level in serum. Fish diseases diagnosis and preventions methods.

Talpur, A.D. \& Ikhwanuddin, M. (2012). Dietary effects of garlic (Allium sativum) on haemato-immunological parameters, survival, growth, and disease resistance against Vibrio harveyi infection in Asian sea bass, Lates calcarifer (Bloch). Aquaculture, 364-365: 6-12. https://doi.org/10.1016/j.aquaculture.2012.07.035

Tang, J., Cai, J., Liu, R., Wang, J., Lu, Y., Wu, Z. \& Jian, J. (2014). Immunostimulatory effects of artificial feed supplemented with a Chinese herbal mixture on Oreochromis niloticus against Aeromonas hydrophila. Fish \& Shellfish Immunology, 39(2): 401-406. https://doi.org/10.1016/j.fsi.2014.05.028

Van Hai, N. (2015). The use of medicinal plants as immunostimulants in aquaculture: A review. Aquaculture, $\quad$ 446: 88-96. https://doi.org/10.1016/j.aquaculture.2015.03.014
Vasudeva Rao, Y., Das, B. K., Jyotyrmayee, P. \& Chakrabarti, R. (2006). Effect of Achyranthes aspera on the immunity and survival of Labeo rohita infected with Aeromonas hydrophila. Fish \& Shellfish Immunology, 20(3): 263273. https://doi.org/10.1016/j.fsi.2005.04.006

Vazirzadeh, A., Dehghan, F. \& Kazemeini, R. (2017). Changes in growth, blood immune parameters and expression of immune related genes in rainbow trout (Oncorhynchus mykiss) in response to diet supplemented with Ducrosia anethifolia essential oil. Fish \& Shellfish Immunology, 69: 164-172. https://doi.org/10.1016/j.fsi.2017.08.022

Vazirzadeh, A., Jalali, S. \& Farhadi, A. (2019). Antibacterial activity of Oliveria decumbens against Streptococcus iniae in Nile tilapia (Oreochromis niloticus) and its effects on serum and mucosal immunity and antioxidant status. Fish \& Shellfish Immunology, 94: 407-416. https://doi.org/10.1016/j.fsi.2019.09.025

Wang, J. \& Sun, R. (2016). Influence of alkaline phosphatase on phase state of the SM monolayers at the air-water interface. Colloids and Surfaces A: Physicochemical and Engineering Aspects, 489: 136-141. https://doi.org/10.1016/j.colsurfa.2015.10.040

Wang, W., Sun, J., Liu, C. \& Xue, Z. (2017). Application of immunostimulants in aquaculture: Current knowledge and future perspectives. Aquaculture Research, 48(1): 123. https://doi.org/10.1111/are.13161

Wu, Y. S., Chen, Y. Y., Ueng, P. S. \& Nan, F. H. (2016). Effects of medicinal herbs "Plantago asiatica", "Houttuynia cordata" and "Mentha haplocalyx" on non-specific immune responses of cobia (Rachycentron canadum). Fish \& Shellfish Immunology, 58: 406-414. https://doi.org/10.1016/j.fsi.2016.09.043

Yeganeh, S., Teimouri, M. \& Amirkolaie, A. K. (2015). Dietary effects of Spirulina platensis on hematological and serum biochemical parameters of rainbow trout (Oncorhynchus mykiss). Research in Veterinary Science, 101: 84-88. https://doi.org/10.1016/j.rvsc.2015.06.002

Yilmaz, S. \& Ergün, S. (2012). Effects of garlic and ginger oils on hematological and biochemical variables of sea bass Dicentrarchus labrax. Journal of Aquatic Animal Health, 24(4): 219-224 https://doi.org/10.1080/08997659.2012.711266 
Yogeshwari, G., Jagruthi, C., Anbazahan, S. M., Mari, L. S. S., Selvanathan, J., Arockiaraj, J., Dhayanithi, N. B., Ajithkumar, T. T., Balasundaram, C. \& Ramasamy, H. (2015). Herbal supplementation diet on immune response in Labeo rohita against Aphanomyces invadans. Aquaculture, 437: 351-359. https://doi.org/10.1016/j.aquaculture.2014.12.024

Zanuzzo, F. S., Urbinati, E. C., Rise, M. L., Hall, J. R., Nash, G. W. \& Gamperl, A. K. (2015). Aeromonas salmonicida induced immune gene expression in Aloe vera fed steelhead trout, Oncorhynchus mykiss (Walbaum). Aquaculture, 435: $1-9$.
Zhang, G., Gong, S., Yu, D. \& Yuan, H. (2009). Propolis and Herba Epimedii extracts enhance the non-specific immune response and disease resistance of Chinese sucker, Myxocyprinus asiaticus. Fish \& Shellfish Immunology, 26(3): 467-472. https://doi.org/10.1016/j.fsi.2009.01.011

Zhou, Q., Wang, L., Wang, H., Xie, F. \& Wang, T. (2012). Effect of dietary vitamin $\mathrm{C}$ on the growth performance and innate immunity of juvenile cobia (Rachycentron canadum). Fish \& Shellfish Immunology, 32(6): 969-975. https://doi.org/10.1016/j.fsi.2012.01.024

https://doi.org/10.1016/j.aquaculture.2014.09.010 